\title{
Crystallization of Zeolite A Coatings from Natural Zeolite
}

\author{
Melkon Tatlier ${ }^{a}$, Çiğdem Atalay-Oral ${ }^{a}$ \\ a Department of Chemical Engineering, Istanbul Technical University, Maslak, Istanbul, Turkey
}

Received: July 28, 2016; Revised: September 20, 2016; Accepted: October 20, 2016

\begin{abstract}
An investigation was carried out to determine the possibility of preparing coatings of synthetic zeolites on stainless steel from mixtures containing natural zeolite. Hydrothermal synthesis was applied and the coatings obtained were characterized by various techniques. It was observed that crystalline zeolite A coatings could be prepared from natural clinoptilolite, which provided the silica necessary for zeolite synthesis in the alkaline reaction mixture containing alumina. Zeolite coating formation was affected by synthesis conditions, such as temperature, time, alkalinity, and alumina content of the reaction mixture. The involvement of two simultaneous processes, namely, dissolution/transformation of clinoptilolite in the mixture and reaction on the substrate by the help of dissolved reagents, presents a new approach for zeolite coating preparation. This method may especially provide a means for more economical mass-scale production of zeolite coatings since the synthetic reagents may be replaced with much cheaper natural resources.
\end{abstract}

Keywords: Natural zeolite, Zeolite A, Coating, Hydrothermal crystallization

\section{Introduction}

Zeolites have many useful existing and potential applications related to adsorption/separation, catalysis and ion-exchange. Utilization of zeolites in the form of coatings, especially when they are directly crystallized on different substrates, may provide significant advantages in many of the applications. Fast heating and cooling of the adsorbent may be achieved, owing to the firm contact between zeolite crystals and substrate eliminating heat transfer resistances ${ }^{1,2}$. A superior control over mass transfer within the adsorbent may also be provided by adjusting the thickness and texture of the coating. Besides this, the preparation of zeolite coatings is important for other reasons, too, such as the reduction of pressure drop in catalysis ${ }^{3}$, adsorption ${ }^{4}$ and membrane/ separation ${ }^{5,6}$ applications.

Zeolite coatings may be prepared by different techniques, the simplest of which involves the immersion of the substrate into the reaction mixture heated by a water bath/oven. This conventional synthesis method is often insufficient in providing coatings with desired properties for different zeolites and applications. Growing both thick and thin coatings may be difficult. One of the extreme cases is zeolite A for which coating thicknesses higher than $5 \mu \mathrm{m}$ can hardly be achieved in one conventional synthesis step ${ }^{7}$. The texture and stability of zeolite coatings are other significant issues that should be taken into consideration. Very firm coatings do not promote diffusion in the adsorbent layer and stability does not profit from this type of texture, either.

Different techniques may be applied for obtaining relatively thick or thin coatings. The substrate heating method promotes the growth of relatively thick coatings in one synthesis step ${ }^{7}$.

* e-mail: tatlierm@itu.edu.tr
In this method, the metal is heated directly while the reaction mixture is kept at a lower temperature in a water/oil bath. Due to a temperature difference between the reaction mixture and the substrate, the crystallization in the bulk is suppressed, while that on the metal surface is promoted. Much thicker coatings of zeolite are thus obtained on the substrate, as compared to conventional synthesis. In order to grow ultrathin coatings, the seed film method may be utilized. This is a multi-step method where firstly the substrate is pre-treated for a surface charge reversal followed by the electrostatical adsorption of colloidal crystals of molecular sieves onto the substrate surface. Finally, crystals are induced to grow into a dense and continuous film of inter-grown crystals under hydrothermal conditions ${ }^{8}$. Covering the substrate surface initially by seed crystals via different methods, such as spincoating ${ }^{9}$ or by dip-coating ${ }^{10}$ prior to the secondary growth of the seeds presents another possibility to control the coating thickness and continuity. In some cases, the support material is used as a source of reactant. The partial transformation of aluminum substrates in the synthesis solution is a typical example while silica based substrates, such as glass may also act as both the support and reactant source in the reaction, leading to zeolite crystallization.

Clinoptilolite is one of the zeolites most commonly observed in the nature. It is used in different applications, mostly based on its ion-exchange properties. The applications include agriculture, horticulture, nuclear waste management, purification of water and the treatment of industrial and urban wastewaters, reduction of the concentration of heavy metals and hazardous substances in plants and environmental matrices ${ }^{11}$. Clinoptilolite and in general natural zeolites have been used in a few applications in the form of coatings or 
membranes. As one example, disk membranes were generated from natural clinoptilolite-rich rock $^{12}$. These membranes were reported to show promising water desalination and de-oiling performance. Additionally, clinoptilolite from the British Columbia deposit was also machined into thin membranes and used in the pervaporative desalination of water samples with varying salinity levels, including synthetic seawater ${ }^{13}$. In another study, ceramic multilayer micro-filtration membranes were obtained on a porous support by dip coating of natural zeolite, as the starting material ${ }^{14}$. The preparation processes including zeolite powder sedimentation, semi-dry pressing, sintering of the support and the membranes, and dip coating of layers were systematically studied. As another example, natural mordenite disks were used in lab-scale ethane dehydrogenation experiments in a membrane reactor to obtain increases in ethane conversion and ethylene yield compared to their equilibrium values ${ }^{15}$.

Raw materials, such as natural zeolites, coal fly ash and kaolin have been used to provide more economical production of synthetic zeolites, which generally have higher economic value. The natural zeolite clinoptilolite has been observed to transform into synthetic zeolites through its treatment in alkaline mixtures containing aluminum. Clinoptilolite has been used mainly as the silica source in such synthesis. The hydrothermal transformation of $\mathrm{Na}$ and $\mathrm{K}$ clinoptilolite was studied by characterizing the solid intermediate phases ${ }^{16}$. Clinoptilolite partially dissolved and an amorphous gel formed prior to the crystallization of any zeolitic phase, the nature of which depended on the cation present in the original material. For the Na form, firstly faujasite crystallized which was further transformed to zeolite $\mathrm{P}$. When $\mathrm{Na}$ in clinoptilolite was replaced by $\mathrm{K}$, only zeolite $\mathrm{P}$ was obtained. In other studies, it was determined that submicron particles of zeolite A powder formed at certain ratios of $\mathrm{Na}_{2} \mathrm{O} / \mathrm{Al}_{2} \mathrm{O}_{3}, \mathrm{Na}_{2} \mathrm{O} /$ clinoptilolite and suitable synthesis temperatures and times from clinoptilolite under hydrothermal synthesis with one or more steps ${ }^{17,18}$. Furthermore, ZSM-5 catalysts were prepared through hydrothermal reaction conducted with $\mathrm{HCl}$-treated clinoptilolite ${ }^{19}$ while mesoporous molecular sieve MCM-41 and zeolite P were synthesized from natural clinoptilolite and cetyltrimethylammonium bromide under hydrothermal conditions in alkaline media ${ }^{20}$. In the latter study, XRD and TG results exhibited that at the first stage where the mixture of clinoptilolite and cetyltrimethylammonium bromide was treated in alkaline media at ambient temperature, crystal structure of clinoptilolite did not change significantly. At the second stage where the mixture was subsequently treated under hydrothermal conditions, dissolution of clinoptilolite and formation of zeolite $\mathrm{P}$ were observed while at the third stage, mesostructure of MCM-41 with 2d hexagonal symmetry was gradually formed by the adjustment of $\mathrm{pH}$ of the reaction mixture.

There are no studies in the literature, to our knowledge, dealing with the crystallization of synthetic zeolite coatings that use natural zeolites or other natural materials as a resource. Coating preparation under such conditions is not straightforward due to the involvement of two simultaneous processes, namely, dissolution/transformation of natural material in the reaction mixture and reaction on the substrate by the help of dissolved reagents.

In this study, the possibility of preparing zeolite A coatings from reaction mixtures containing natural clinoptilolite was investigated. Different synthesis conditions were used for direct crystallization of zeolite on stainless steel plates immersed into the mixtures containing sodium hydroxide and sodium aluminate besides natural zeolite. The coatings prepared were characterized by X-ray diffraction (XRD), field emission gun scanning electron microscopy (FEGSEM) and thermogravimetry (TG).

\section{Experimental}

\subsection{Materials}

Zeolite coatings were grown on stainless steel plates (AISI 316 grade). The plates had about $1 \mathrm{~cm}$ diameter and $0.5 \mathrm{~mm}$ thickness. Coatings were prepared by conventional synthesis and substrate heating methods. When the substrate heating method was used, the device was similar to those described in previous studies ${ }^{7}$ and was composed of a polypropylene vessel $(0.5 \mathrm{~L})$, a heating resistance $(30 \mathrm{~W})$ and a stainless steel rod covered with Teflon. The resistance was inserted into the rod. The Teflon surrounding the metal rod had an opening (of about $0.8 \mathrm{~cm}$ diameter) at the lower side where the plate was placed vertically on an extension of the rod. The system was immersed into the reaction mixture in the polypropylene vessel. The temperature was measured by a thermocouple placed on the metal rod near the heating resistance. The polypropylene vessel was kept in a water bath. In the experiments utilizing conventional synthesis, the stainless steel plate was simply immersed vertically in the reaction mixture by the help of a Teflon holder.

The chemical composition of the clinoptilolite-rich rock used in the synthesis experiments mainly consisted of (in wt\%) $66.17 \mathrm{SiO}_{2}: 9.72 \mathrm{Al}_{2} \mathrm{O}_{3}: 14.47 \mathrm{H}_{2} \mathrm{O}: 0.134 \mathrm{Na}_{2} \mathrm{O}$ : 1.50 K $\mathrm{K}_{2} \mathrm{O}: 2.51 \mathrm{CaO}: 0.61 \mathrm{MgO}: 3.19 \mathrm{Fe}_{2} \mathrm{O}_{3}$, as reported before $^{21,22}$. The mineralogical composition of the material, originating from a deposit near Bigadiç, Turkey, mainly consisted of clinoptilolite (about 85\%). Associated minerals were especially quartz and some feldspar. The ground particles were sieved to have a particle size smaller than about $25 \mu \mathrm{m}$. Different reaction mixtures were prepared for performing the syntheses. Granular sodium aluminate (Riedel-de Haen), $\mathrm{NaOH}$ pellets (Carlo Erba), deionized water and natural clinoptilolite were utilized as reagents.

\subsection{Synthesis}

For the preparation of synthesis mixtures, firstly, $\mathrm{NaOH}$ was dissolved in water and then sodium aluminate was 
added to this solution. Finally, when the mixture became clear, clinoptilolite was included to the solution which was mixed further for a few minutes. The stainless steel plate was immersed into this mixture in a manner assuring that it was placed at the top and was not in direct contact with the solid phase, which settled at the bottom of the reactor almost in a few minutes after the synthesis started. A relatively clear solution formed over the solid material and the substrate was situated within this relatively clear region. The coatings were prepared in an oven kept at various temperatures for conventional synthesis. For the substrate heating method, a heating resistance temperature of $140^{\circ} \mathrm{C}$ and two different water bath temperatures of $30^{\circ} \mathrm{C}$ and $75^{\circ} \mathrm{C}$ were used. Under these conditions, the substrate surface temperature was measured to be at about $60^{\circ} \mathrm{C}$ and $90^{\circ} \mathrm{C}$, respectively.

In this study, the reaction mixture with a molar composition of $14 \mathrm{Na}_{2} \mathrm{O}: 1 \mathrm{Al}_{2} \mathrm{O}_{3}: 440 \mathrm{H}_{2} \mathrm{O}\left(\mathrm{C}_{\text {primary }}\right)$ was taken as a basis, by taking into account literature studies related to the conversion of clinoptilolite to zeolite A powder as well as some preliminary investigations. $2.5 \mathrm{~g}$ clinoptilolite was added to most of the reaction mixtures with different compositions, while in two of the compositions, the amounts of clinoptilolite used were different. The amount of water was equal to about $43 \mathrm{~g}$ in all the conventional synthesis experiments. In the substrate heating system, the amount of reaction mixture and clinoptilolite used was about 3 fold higher. The amounts of clinoptilolite, $\mathrm{Al}_{2} \mathrm{O}_{3}$ and $\mathrm{Na}_{2} \mathrm{O}$ as well as synthesis temperature and time were varied to reveal the effects of different synthesis conditions on the formation of zeolite coatings. $14 \mathrm{Na}_{2} \mathrm{O}: 1.5 \mathrm{Al}_{2} \mathrm{O}_{3}: 440 \mathrm{H}_{2} \mathrm{O}\left(\mathrm{C}_{\text {high_Al }}\right)$, $14 \mathrm{Na}_{2} \mathrm{O}: 0.5 \mathrm{Al}_{2} \mathrm{O}_{3}: 440 \mathrm{H}_{2} \mathrm{O}\left(\mathrm{C}_{\text {low_Al }}\right), 10 \mathrm{Na}_{2} \mathrm{O}: 1 \mathrm{Al}_{2} \mathrm{O}_{3}: 440$ $\mathrm{H}_{2} \mathrm{O}\left(\mathrm{C}_{\text {low Na }}\right), 18 \mathrm{Na}_{2} \mathrm{O}: 1 \mathrm{Al}_{2} \mathrm{O}_{3}: 440 \mathrm{H}_{2} \mathrm{O}\left(\mathrm{C}_{\text {high Na }}\right)$ were some of the compositions tested. $\mathrm{C}_{\text {low_Cli }}$ and $\mathrm{C}_{\text {high_Cli }}$ had similar compositions with $\mathrm{C}_{\text {primary }}$ while only the clinoptilolite mass used in them was equal to $2 \mathrm{~g}$ and $3 \mathrm{~g}$, respectively. Prior to the synthesis of the zeolite coatings, the plates were cleaned firstly by toluene followed by a mixture consisting of 1 part (volumetric) $\mathrm{H}_{2} \mathrm{O}_{2}(\% 30), 1$ part $\mathrm{NH}_{4} \mathrm{OH}(\% 25)$ and 5 parts $\mathrm{H}_{2} \mathrm{O}$. Then, the plates were rinsed by deionized water.

\subsection{Characterization techniques}

The coatings were analyzed by X-ray diffraction (Bruker-D8-Advance), field emission gun scanning electron microscopy (FEGSEM) and thermogravimetry (TG). XRD was run for phase identification and determination of the purity of the samples with a $\mathrm{Cu}$ anode tube at $40 \mathrm{kV} / 40 \mathrm{~mA}$, with a Ni filter and constant sample illumination spot size. $\mathrm{CuK} \alpha$ radiation and a step size of $0.02^{\circ}$ with $1.0 \mathrm{~s}$ per step were used. Electron microscopy (JEOL JSM-7000F) was used to investigate the morphology of some of the zeolite coatings. Prior to the FEGSEM examinations, the samples were coated with Pt by magnetron sputtering using a Hitachi E-1030. This operation was performed under $0.1 \mathrm{~Pa}$ argon atmosphere for $30 \mathrm{~min}$. Thermogravimetric (TG) analysis (Shimadzu TA-503) was performed to determine the water desorption between ambient temperature and $350^{\circ} \mathrm{C}$ under nitrogen flow. A heating rate of $20{ }^{\circ} \mathrm{C} / \mathrm{min}$ was used. The TG measurements were repeated in order to determine the crystallinities of the samples. After each synthesis, the coating was removed from the system, rinsed with water, dried in the oven and kept in a desiccator under a controlled humidity atmosphere (saturated $\mathrm{NH}_{4} \mathrm{Cl}$ solution) prior to and after the TG measurements. The samples were weighed at the end of each procedure and their hydrated masses were reported in this study. Commercial zeolite NaA (Aldrich) was used for comparison of TG measurements of the samples. Solid materials obtained from the reaction mixtures by filtration were also analyzed by XRD and TG measurements. Chemical analyses were performed to determine the compositions of the clear portions of the reaction mixtures. Accordingly, samples were taken from the top of the mixtures, representing clear solutions. Inductively Coupled Plasma-Mass Spectrometer (ICP-MS) (Thermo Fisher Scientific) was used for performing the chemical analyses. The digestion of the samples was carried out by utilizing an acid mixture consisting of $4 \mathrm{ml}$ $65 \% \mathrm{HNO} 3,1 \mathrm{ml} \mathrm{37 \%} \mathrm{HCl}$ and $4 \mathrm{ml} \mathrm{40 \%} \mathrm{HF}$ for $15 \mathrm{~min}$ at $210^{\circ} \mathrm{C}$ in a microwave oven (Anton Paar Multiwave 3000 ).

\section{Results and discussion}

Zeolite A coatings could be prepared on stainless steel from mixtures containing clinoptilolite both when conventional and substrate heating synthesis methods were used. Table 1 reports the masses and phases of the coatings prepared by conventional synthesis in this study. Investigations were also performed regarding the solid powder materials obtained by filtration (particles with size $>2 \mu \mathrm{m}$ ) from the reaction mixtures. The properties of these materials, which may provide information about activities in the bulk phase, are also given in the table. When composition $\mathrm{C}_{\text {primary }}$ was used, zeolite A coatings were obtained between 2.5 and $5.5 \mathrm{~h}$ of synthesis. The coating mass increased with synthesis time and temperature. Both lowering and increasing the aluminum content of the reaction mixture $\mathrm{C}_{\text {primary }}$ led to reductions in coating mass. Increasing the alkalinity provided some increase in coating mass while decreasing the alkalinity hindered coating formation under the studied conditions. As the mass of clinoptilolite used in the reaction mixture was reduced, the coating mass decreased while increasing the clinoptilolite content did not result in significant change of the coating amount.

The XRD patterns of the coatings prepared from composition $\mathrm{C}_{\text {primary }}$ after $3.5,4.5,5.5$ and $18 \mathrm{~h}$ of conventional synthesis at $90^{\circ} \mathrm{C}$ are shown in Figure 1. Zeolite A might be observed to be the only phase present in the first three samples. The intensities of the XRD peaks increased with synthesis time, parallel to the increase in coating mass. After $18 \mathrm{~h}$ of synthesis, although there was still zeolite A in the coating, a mixed phase was obtained in which 
Table 1: Masses and phases of coatings and bulk phase solid materials obtained by conventional synthesis (A: zeolite A, HS: hydroxysodalite, ERI: erionite, CL: clinoptilolite).

\begin{tabular}{|c|c|c|c|c|c|c|}
\hline \multirow{2}{*}{ Synthesis composition } & \multirow{2}{*}{ Synthesis time (h) } & \multirow{2}{*}{$\begin{array}{c}\text { Synthesis temperature } \\
\left({ }^{\circ} \mathrm{C}\right)\end{array}$} & \multicolumn{2}{|c|}{ Mass } & \multicolumn{2}{|c|}{ Phase } \\
\hline & & & Coating (mg) & Bulk (g) & Coating & Bulk \\
\hline \multirow{9}{*}{$\mathrm{C}_{\text {primary }}$} & 0.5 & 90 & - & 2.32 & - & $\mathrm{CL}$ \\
\hline & 1.5 & 90 & - & 3.31 & - & A \\
\hline & 2.5 & 90 & 0.4 & 3.10 & A & A \\
\hline & 3.5 & 90 & 0.9 & 2.77 & A & $\mathrm{A}$ \\
\hline & 4.5 & 90 & 1.4 & 2.68 & A & A \\
\hline & 5.5 & 90 & 1.9 & 2.55 & A & $\mathrm{A}+\mathrm{HS}$ \\
\hline & 18 & 90 & 3.8 & 3.22 & $\mathrm{~A}+\mathrm{HS}+\mathrm{ERI}$ & $\mathrm{A}+\mathrm{HS}+\mathrm{ERI}$ \\
\hline & 4.5 & 81 & 0.7 & 2.52 & A & A \\
\hline & 4.5 & 99 & 2.1 & 2.63 & $\mathrm{~A}+\mathrm{HS}$ & $\mathrm{A}+\mathrm{HS}$ \\
\hline $\mathrm{C}_{\text {high_Al }}$ & 4.5 & 90 & 0.5 & 2.90 & $\mathrm{~A}+\mathrm{HS}+\mathrm{CL}$ & $\mathrm{A}+\mathrm{HS}+\mathrm{CL}$ \\
\hline & 4.5 & 90 & 0.5 & 3.05 & $\mathrm{~A}$ & A \\
\hline $\mathrm{C}_{\text {low_Al }}$ & 6 & 90 & 0.9 & 2.95 & A & $\mathrm{A}+\mathrm{HS}$ \\
\hline $\mathrm{C}_{\text {low_Na }}$ & 4.5 & 90 & - & 2.43 & - & A \\
\hline $\mathrm{C}_{\text {high_Na }}$ & 4.5 & 90 & 2.0 & 2.62 & $\mathrm{~A}+\mathrm{HS}$ & $\mathrm{A}+\mathrm{HS}$ \\
\hline $\mathrm{C}_{\text {low_Cli }}$ & 4.5 & 90 & 0.5 & 2.32 & A & A \\
\hline $\mathrm{C}_{\text {high_Cli }}$ & 4.5 & 90 & 1.5 & 3.16 & A & A \\
\hline
\end{tabular}

hydroxysodalite seemed to be the most abundant zeolite. Small peaks of erionite were also detected in this sample. According to XRD results, zeolite A was still present in the samples obtained from composition $\mathrm{C}_{\text {primary }}$ at relatively lower and higher temperatures of $81^{\circ} \mathrm{C}$ and $99^{\circ} \mathrm{C}$ after 4.5 $\mathrm{h}$ of synthesis (see Table 1). The coating prepared at $81^{\circ} \mathrm{C}$ was less crystalline. At the higher temperature of $99^{\circ} \mathrm{C}$, a small amount of hydroxysodalite also formed besides the dominant zeolite A phase. Increasing the Al content of composition $\mathrm{C}_{\text {primary }}$ (composition $\mathrm{C}_{\text {high_Al }}$ ) did not favor zeolite A formation and a mixed phase occurred at $90^{\circ} \mathrm{C}$ after $4.5 \mathrm{~h}$ of synthesis. Besides zeolite A, hydroxysodalite and residual clinoptilolite were also detected in this sample. On the other hand, decreasing the $\mathrm{Al}$ content (composition $\mathrm{C}_{\text {low_Al }}$ ) still allowed zeolite A formation even though amorphous material also seemed to exist. The crystallinity increased when the synthesis time was extended to $6 \mathrm{~h}$ at $90^{\circ} \mathrm{C}$. When the amount of sodium was reduced (composition $\mathrm{C}_{\text {low Na }_{\mathrm{Na}}}$ ), no observable coating formed on the stainless steel plate indicating that a decrease in the alkalinity of the reaction mixture did not promote synthesis of zeolite A or other phases after $4.5 \mathrm{~h}$ at $90^{\circ} \mathrm{C}$. Increasing the alkalinity (composition $\mathrm{C}_{\text {high_Na }}$ ) resulted in a small amount of hydroxysodalite besides zeolite $\mathrm{A}$ in this sample. When the amount of clinoptilolite used was reduced to $2 \mathrm{~g}$ (composition $\mathrm{C}_{\text {low Cli }}$ ) and enhanced to $3 \mathrm{~g}$ (composition $\mathrm{C}_{\text {high_Cli }}$ ) for syntheses performed after $4.5 \mathrm{~h}$ of synthesis at $90^{\circ} \mathrm{C}$, zeolite A still formed.

The TG curves of the coatings prepared from composition $\mathrm{C}_{\text {primary }}$ after different synthesis times at $90^{\circ} \mathrm{C}$ are given in Figure 2. The TG curve of commercial zeolite NaA powder is also shown in the figure. It may be observed that the water loss of the samples approached to that of commercial zeolite $\mathrm{NaA}$ as the synthesis time was increased from $3.5 \mathrm{~h}$ to $5.5 \mathrm{~h}$. Table 2 reports the amount of water loss from the coatings as well as from commercial zeolite NaA powder after the first (shown in Figure 2) and second TG measurements performed for each sample. The second measurements may give indications about the crystallinities of the materials since amorphous materials may generally be expected to lose their water storage capacity after the first adsorption/ desorption at a relatively high temperature. The second TG measurements revealed capacity reductions of about $16 \%$, $12 \%$ and $6 \%$, compared to the first measurements, for the coatings prepared after $3.5 \mathrm{~h}, 4.5 \mathrm{~h}$ and $5.5 \mathrm{~h}$ of synthesis, respectively. From these results, the crystallinities of the samples may be assumed to increase with synthesis time, as also indicated by XRD results. The capacity of the sample prepared after $18 \mathrm{~h}$ of synthesis was quite lower. The presence of crystalline phases/amorphous materials less hydrophilic than zeolite A led to a lower water loss for this sample.

FEGSEM micrographs of the coating grown on stainless steel from composition $\mathrm{C}_{\text {primary }}$ after $5.5 \mathrm{~h}$ of synthesis are given in Figure 3 at different magnifications. It may be observed that a closed layer was formed on the substrate after this synthesis time. The mass equivalent thickness of this continuous coating was about $19 \mu \mathrm{m}$, which represented the highest zeolite A coating thickness obtained in this study by using conventional synthesis. Mass equivalent thickness may be defined as (mass of zeolite deposited per coated area of substrate)/(density of zeolite). Hydrated zeolite A density 


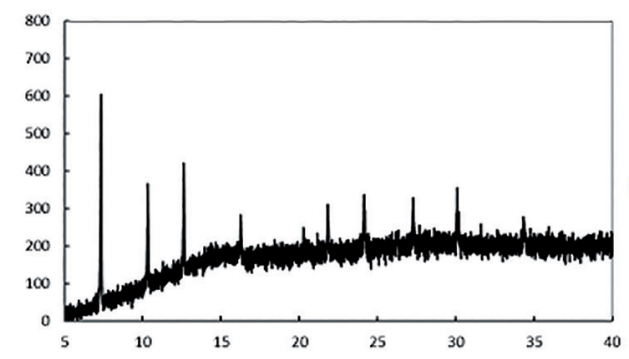

(a)

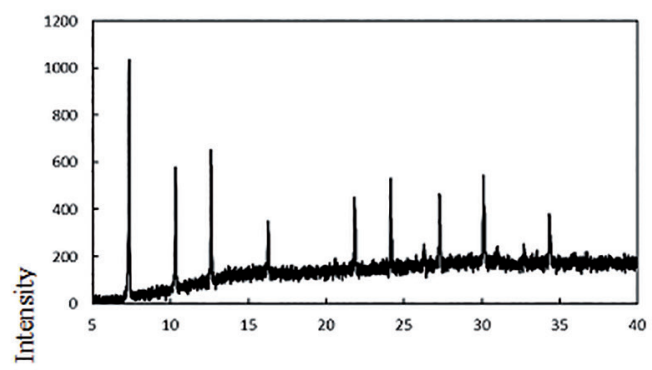

(b)
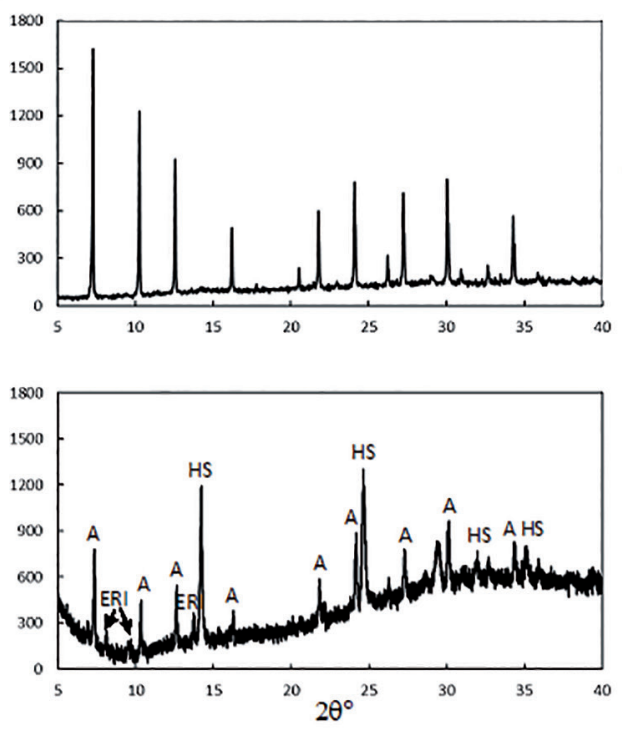

Figure 1. XRD patterns of the coatings prepared from composition $\mathrm{C}_{\text {primary }}$ after (a) $3.5 \mathrm{~h}$, (b) $4.5 \mathrm{~h}$, (c) $5.5 \mathrm{~h}$ and (d) $18 \mathrm{~h}$ of conventional synthesis at $90{ }^{\circ} \mathrm{C}$

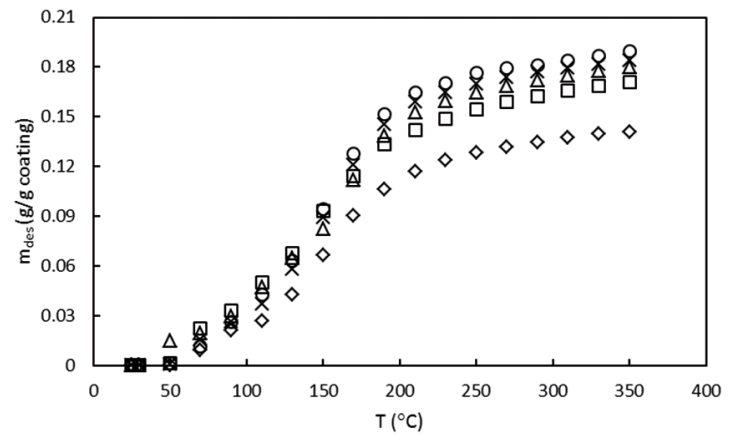

Figure 2: TG curves of coatings prepared after $(\square) 3.5$ h, $(\Delta) 4.5$ $\mathrm{h},(\mathrm{x}) 5.5 \mathrm{~h}$ and $(\diamond) 18 \mathrm{~h}$ of conventional synthesis at $90{ }^{\circ} \mathrm{C}$ from composition $\mathrm{C}_{\text {primary }}$ and TG curve of (o) commercial zeolite A powder.
Table 2: Desorption capacities of coatings prepared from composition $\mathrm{C}_{\text {primary }}$ at $90{ }^{\circ} \mathrm{C}$ by conventional synthesis and the capacity of commercial zeolite A powder. $\mathrm{m}_{\text {des } 1}$ and $\mathrm{m}_{\text {des } 2}$ denote the first and second TG measurements performed for each sample.

\begin{tabular}{lcc}
\hline Synthesis time $(\mathrm{h})$ & $\mathrm{m}_{\text {des } 1}(\mathrm{~g} / \mathrm{g}$ coating $)$ & $\mathrm{m}_{\text {des } 2}(\mathrm{~g} / \mathrm{g}$ coating $)$ \\
\hline 3.5 & 0.170 & 0.143 \\
4.5 & 0.179 & 0.158 \\
5.5 & 0.183 & 0.172 \\
18 & 0.141 & 0.121 \\
Zeolite A & 0.189 & 0.180 \\
\hline
\end{tabular}

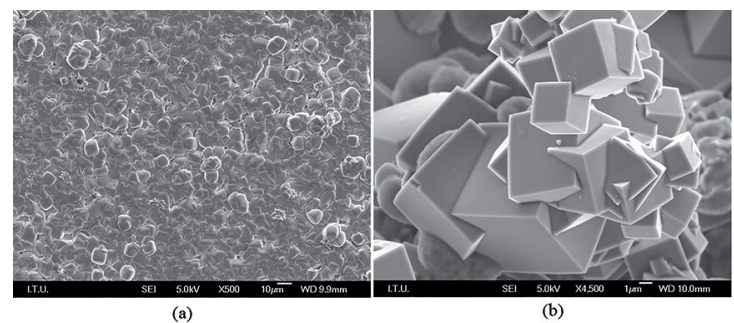

Figure 3: FEGSEM micrographs of the coating grown from composition $\mathrm{C}_{\text {primary }}$ at $90{ }^{\circ} \mathrm{C}$ after $5.5 \mathrm{~h}$ of conventional synthesis, as shown at magnifications of (a) $\times 500$ and (b) $\times 4500$.

of $2 \mathrm{~g} / \mathrm{cm}^{3}$ was used in the calculations. Particles of around 5-10 $\mu \mathrm{m}$ were commonly observed in the coating. A quite crystalline zeolite A was also indicated by the XRD and TG results for this sample.

As mentioned before, the solid powder materials obtained by filtration from the reaction mixtures were also investigated. The masses and phases of these materials are shown in Table 1 for the conventional synthesis experiments. It should be remembered that the amount of clinoptilolite added initially to the reaction mixture was equal to $2.5 \mathrm{~g}$ except for the compositions $\mathrm{C}_{\text {low_Cli }}$ and $\mathrm{C}_{\text {high_Cli }}$ where $2 \mathrm{~g}$ and $3 \mathrm{~g}$ of clinoptilolite were used, respectively. The variations in the masses of the solid materials obtained from the bulk of the reaction mixtures indicated the presence of different stages of synthesis in the system. When there is no significant formation of synthetic zeolite in the reaction mixture, the dissolution of clinoptilolite (and after its transformation starts, amorphous material) may result in a reduction of solid material in the mixture. As zeolite synthesis begins, the amount of solid materials may be expected to increase, also depending on the competitive rates of clinoptilolite/ amorphous material dissolution and synthetic zeolite formation in the reaction mixture. Actually, when composition $\mathrm{C}_{\text {primary }}$ was used, the mass of solid material in the reaction mixture, which was initially equal to $2.5 \mathrm{~g}$ (clinoptilolite mass), firstly decreased (after $0.5 \mathrm{~h}$ of synthesis) and then increased (after $1.5 \mathrm{~h}$ of synthesis). The mass of solid material started to decrease once more after $2.5 \mathrm{~h}$ of synthesis. This tendency continued until $18 \mathrm{~h}$ of synthesis when the mass increased again. The second decrease observed after $2.5 \mathrm{~h}$ of synthesis was probably related to the slowing down of zeolite A 
synthesis in the reaction mixture. During this period, the dissolution of clinoptilolite/amorphous material seemed to be more significant than zeolite formation. When there was not much of amorphous material left in the reaction mixture for dissolution, e.g., after $18 \mathrm{~h}$ of synthesis, the solid mass in the bulk phase increased once again, due to the still ongoing synthesis, especially of zeolite HS.

XRD indicated the presence of mainly zeolites A and HS in the solid material samples collected from the reaction mixtures. However, amorphous materials existed in large quantities in almost all the samples, as also described below by the TG investigations. Only the crystalline phases are mentioned in Table 1. The zeolite phases in the coatings and solid materials were mostly similar for the use of same synthesis conditions, though there were a few differences, which might originate from composition variations in the different parts of the reaction mixture, due to static synthesis conditions. It may be observed from Table 1 that in the sample obtained at a very early synthesis time of half an hour from composition $\mathrm{C}_{\text {primary }}$, there was still a lot of clinoptilolite, while amorphous material also started to form. After this time, zeolite A and then zeolite HS started to form in the bulk phase, coexisting with amorphous material. Figure 4 represents the XRD pattern of the solid material obtained from the reaction mixture with composition $\mathrm{C}_{\text {primary }}$ after $4.5 \mathrm{~h}$ of synthesis at $90^{\circ} \mathrm{C}$. It may be seen that zeolite A and amorphous material existed in this sample. Table 3 reports the desorption capacities of the samples after the first and second TG measurements performed for each sample. The capacities of the clinoptilolite-rich material and commercial zeolite $\mathrm{NaA}$ powder are also shown in the table for comparison. As mentioned before, the second measurements may give indications about the crystallinities of the materials. Accordingly, crystallinity seemed to be relatively high immediately after the beginning of synthesis at $0.5 \mathrm{~h}$. However, it dropped significantly after this period of time. Clinoptilolite was still present at the very early synthesis periods, especially at $0.5 \mathrm{~h}$, which should be the reason for the relatively high crystallinity at this time. The other seemingly high crystallinity was obtained for the synthesis time of $18 \mathrm{~h}$ investigated, which seemed to indicate that the amorphous material was then mostly converted to zeolites A and HS and/or a high amount of these zeolites was formed in the reaction mixture. The initial desorption capacities of the samples tended to increase significantly as the synthesis time was enhanced up to $5.5 \mathrm{~h}$ of synthesis. This tendency may be explained by the formation of zeolite A in the samples as well as some changes gradually taking place in the amorphous material.

Zeolite A coatings could also be prepared by using the substrate heating method. Table 4 reports the masses and phases of the coatings prepared by this synthesis method from composition $\mathrm{C}_{\text {primary }}$. Properties of the solid materials obtained from the bulk phase under the same synthesis conditions

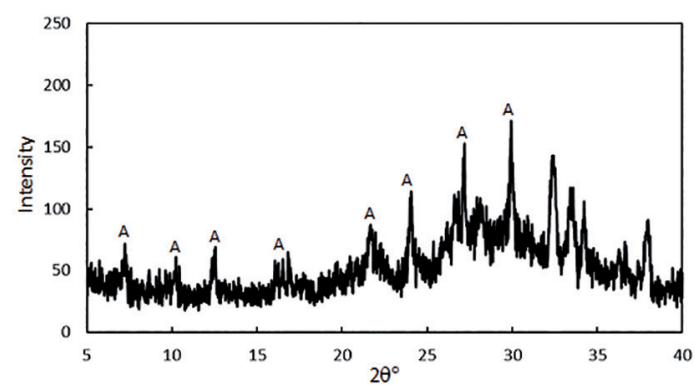

Figure 4: XRD pattern of the powder material formed in the reaction mixture with composition $\mathrm{C}_{\text {primary }}$ after $4.5 \mathrm{~h}$ of conventional synthesis at $90^{\circ} \mathrm{C}$.

Table 3: Desorption capacities of powder samples obtained from composition $\mathrm{C}_{\text {primary }}$ at $90{ }^{\circ} \mathrm{C}$ by conventional synthesis and the capacities of commercial zeolite $\mathrm{A}$ and clinoptilolite powder. $\mathrm{m}_{\mathrm{des}}$ and $\mathrm{m}_{\mathrm{des} 2}$ denote the first and second TG measurements performed for each sample.

\begin{tabular}{lcc}
\hline Synthesis time $(\mathrm{h})$ & $\mathrm{m}_{\text {des } 1}(\mathrm{~g} / \mathrm{g}$ sample $)$ & $\mathrm{m}_{\text {des } 2}(\mathrm{~g} / \mathrm{g}$ sample $)$ \\
\hline 0.5 & 0.116 & 0.086 \\
1.5 & 0.125 & 0.042 \\
3.5 & 0.137 & 0.037 \\
4.5 & 0.147 & 0.046 \\
5.5 & 0.165 & 0.054 \\
18 & 0.154 & 0.134 \\
Zeolite A & 0.189 & 0.180 \\
Clinoptilolite & 0.103 & 0.095 \\
\hline
\end{tabular}

Table 4: Masses and phases of coatings and bulk phase solid materials obtained by substrate heating method (A: zeolite A, Am: amorphous material).

\begin{tabular}{|c|c|c|c|c|c|}
\hline \multirow{2}{*}{$\begin{array}{l}\text { Synthesis } \\
\text { time (h) }\end{array}$} & \multirow{2}{*}{$\begin{array}{c}\text { Synthesis } \\
\text { temperature } \\
\left({ }^{\circ} \mathrm{C}\right)\end{array}$} & \multicolumn{2}{|c|}{ Mass } & \multicolumn{2}{|c|}{ Phase } \\
\hline & & $\begin{array}{c}\text { Coating } \\
\text { (mg) }\end{array}$ & $\begin{array}{c}\text { Bulk } \\
(\mathrm{g})\end{array}$ & $\begin{array}{c}\text { Coating } \\
\text { (mg) }\end{array}$ & Bulk (g) \\
\hline 4.5 & $75-140$ & 2.9 & 8.06 & A & A \\
\hline 1.5 & $30-140$ & - & 6.88 & - & Am \\
\hline 16 & $30-140$ & 0.2 & 6.52 & A & $\mathrm{Am}$ \\
\hline 27 & $30-140$ & 0.5 & 6.57 & A & $\mathrm{Am}$ \\
\hline 42 & $30-140$ & 2.2 & 6.64 & A & $\mathrm{Am}$ \\
\hline
\end{tabular}

are also given in the table. It may be seen that when water bath and heating resistance temperatures of $30^{\circ} \mathrm{C}$ and $140^{\circ} \mathrm{C}$ were used, the coating mass increased with synthesis time. Increasing the temperature of the water bath to $75^{\circ} \mathrm{C}$ led to a relatively higher coating mass at a quite shorter synthesis time. Figure 5a and Figure 5b represent the XRD patterns of the coatings prepared from composition $\mathrm{C}_{\text {primary }}$ after $4.5 \mathrm{~h}$ of synthesis at a $75^{\circ} \mathrm{C}$ water bath temperature and after $16 \mathrm{~h}$ of synthesis at a $30^{\circ} \mathrm{C}$ water bath temperature, respectively. From Figure 5a, zeolite A was the only phase in the first coating while from Table 4, its mass was higher (about two fold) than that obtained by conventional synthesis at the same 


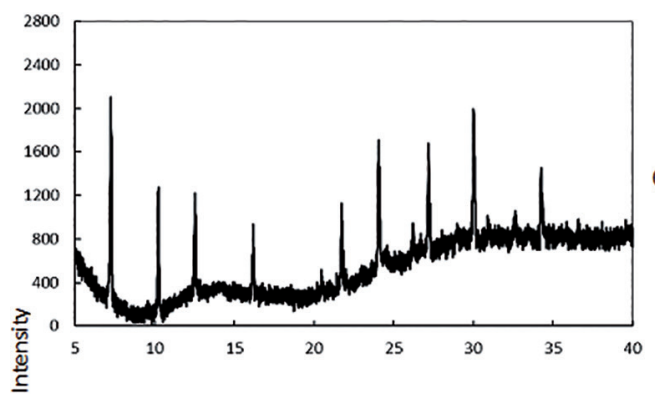

(a)

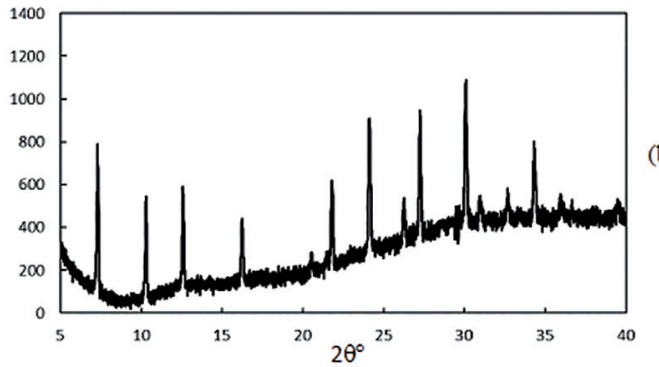

Figure 5: XRD patterns of the coatings prepared by substrate heating method from composition $\mathrm{C}_{\text {primary }}$ a) after $4.5 \mathrm{~h}$ of synthesis at water bath and heating resistance temperatures of $75^{\circ} \mathrm{C}$ and 140 ${ }^{\circ} \mathrm{C}$, respectively and $\mathrm{b}$ ) after $16 \mathrm{~h}$ of synthesis at water bath and heating resistance temperatures of $30^{\circ} \mathrm{C}$ and $140{ }^{\circ} \mathrm{C}$, respectively.

synthesis duration and about the same substrate temperature. The crystallinity of this sample seemed to be somewhat less than that of the sample prepared after $4.5 \mathrm{~h}$ of conventional synthesis (XRD diffractogram in Figure 1b). The reason for the mass increase might be related to the more effective and rapid heating of the metal plate by conduction in the substrate heating method, when compared to heating by convection in an oven. When the water bath temperature was decreased considerably to $30^{\circ} \mathrm{C}$, pure zeolite A still formed, as observed from Figure $5 \mathrm{~b}$, but at a longer duration and the amount of zeolite was less. Since clinoptilolite mostly settled at the bottom of the reaction mixture, which was at about $30-35^{\circ} \mathrm{C}$ according to the synthesis conditions, it may be deduced that the dissolution/transformation of clinoptilolite occurred at this quite low temperature, too. Consequently, zeolite A could crystallize on stainless steel plates kept at a higher temperature, by using silica from dissolved clinoptilolite. The possibility of using substrate heating method in the synthesis provided by the transformation of clinoptilolite in an alkaline reaction mixture is significant since this method may allow the preparation of relatively thick coatings at prolonged durations, especially for metastable phases, such as zeolite A, which may transform readily into more stable phases.

FEGSEM micrographs of the coating grown by the substrate heating method on stainless steel from composition $\mathrm{C}_{\text {primary }}$ after $42 \mathrm{~h}$ of synthesis at water bath and heating resistance temperatures of $30^{\circ} \mathrm{C}$ and $140^{\circ} \mathrm{C}$, respectively, are given in Figure 6 at different magnifications. It may be observed that this coating was relatively inhomogeneous in

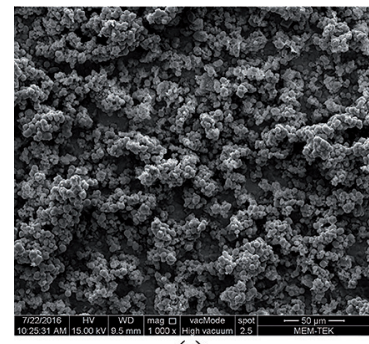

(a)

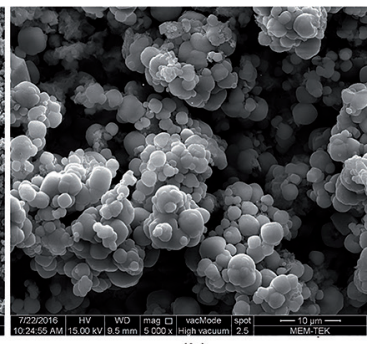

(b)
Figure 6: FEGSEM micrographs of the coating grown by using substrate heating method at water bath and heating resistance temperatures of $30{ }^{\circ} \mathrm{C}$ and $140{ }^{\circ} \mathrm{C}$, respectively, after $42 \mathrm{~h}$ of synthesis, as shown at magnifications of (a) x1000 and (b) x5000.

nature and the particles were generally of a few microns. Actually, the substrate heating method often leads to open sponge-like zeolite coatings with intracrystalline macrovoids, which promote diffusion in these materials. The mass equivalent thickness of this coating was about $22 \mu \mathrm{m}$. The thickest zeolite A coating of about $29 \mu \mathrm{m}$ prepared in this study was that obtained by using substrate heating method after $4.5 \mathrm{~h}$ of synthesis at water bath and heating resistance temperatures of $75^{\circ} \mathrm{C}$ and $140^{\circ} \mathrm{C}$, respectively.

All the coatings obtained in this study by using the substrate heating method were pure zeolite A. On the other hand, as may be observed from Table 4, solid materials obtained from the bulk phase were generally amorphous materials at the lower water bath temperature of $30^{\circ} \mathrm{C}$. Zeolite A was observed in the bulk phase only when the higher water bath temperature of $75^{\circ} \mathrm{C}$ was utilized. The mass of clinoptilolite added to the reaction mixture was equal to $7.5 \mathrm{~g}$ in the substrate heating system, due to the larger amount of reaction mixture used. For the cases utilizing a water bath temperature of $30^{\circ} \mathrm{C}$, the mass of solid material obtained from the bulk of the reaction mixture was observed to decrease sharply from the initial amount of $7.5 \mathrm{~g}$ after $1.5 \mathrm{~h}$ of synthesis, decrease some more after $16 \mathrm{~h}$ of synthesis and then remain nearly constant. This indicates that not much synthesis activity took place in the bulk of the reaction mixture, which was kept at a quite low temperature of $30^{\circ} \mathrm{C}$. The dissolution of clinoptilolite/amorphous material mainly determined the masses of the solid materials obtained from the reaction mixtures. The substrate heating method aims to promote synthesis on the substrate while suppressing that in the bulk of the reaction mixture. When the higher temperature of $75^{\circ} \mathrm{C}$ was used for the water bath, the amount of solid materials in the bulk phase surpassed $7.5 \mathrm{~g}$, indicating significant zeolite A synthesis taking place in the reaction mixture as well as on the substrate.

Chemical analyses were performed to determine the compositions of the reaction mixtures during crystallization of zeolite coatings. Accordingly, samples that might be described as clear solutions, were taken from the top of the mixtures. The results obtained for conventional and substrate heating 
synthesis methods again revealed the difference in the natures of these two techniques. A clear solution sample taken after $4.5 \mathrm{~h}$ of conventional synthesis from the reaction mixture with composition $\mathrm{C}_{\text {primary }}$ at $90^{\circ} \mathrm{C}$ indicated a molar composition of $260.3 \mathrm{Na}_{2} \mathrm{O}: 1 \mathrm{Al}_{2} \mathrm{O}_{3}: 1.2 \mathrm{SiO}_{2}: 5878.5 \mathrm{H}_{2} \mathrm{O}$. It seems that at this stage of conventional synthesis, alumina and silica in the reaction mixture, as limiting reactants, were reduced to a great extent, due to the already excessive formation of zeolite A. Another clear solution sample was taken after 27 $\mathrm{h}$ of synthesis from the substrate heating synthesis system at water bath and heating resistance temperatures of $30^{\circ} \mathrm{C}$ and $140^{\circ} \mathrm{C}$, respectively. In this case, the molar composition was determined to be $9.7 \mathrm{Na}_{2} \mathrm{O}: 1 \mathrm{Al}_{2} \mathrm{O}_{3}: 0.1 \mathrm{SiO}_{2}: 96.6$ $\mathrm{H}_{2} \mathrm{O}$. Here, the relative abundance of aluminum seems to be noteworthy, indicating that not much reaction took place in the mixture. The decrease in the sodium oxide/alumina ratio might indicate that some aluminum besides silicon also entered the solution phase from the dissolving clinoptilolite/ amorphous material.

In the syntheses where natural clinoptilolite is used as a natural resource, coating formation takes place on the metal substrate as transformations start to occur in the clinoptilolite in the reaction mixture. Since there is no synthetic silica reagent in the reaction mixture, the silica needed for forming zeolite should be obtained from the dissolution of clinoptilolite. It is possible that aluminum and sodium from the natural zeolite may also contribute to the zeolite A coating formation on the substrate. An important profit of using natural zeolite for producing coatings of synthetic zeolites is surely the improved economics, especially when these materials are required to be used in large amounts in various applications. Replacing the synthetic silica source required for zeolite synthesis with a much cheaper natural zeolite should contribute to a more profitable coating production process. As an example, considering the use of similar amounts of sodium aluminate (the limiting reagent) in composition $\mathrm{C}_{\text {primary }}$ of this study and in $50 \mathrm{Na}_{2} \mathrm{O}: 1 \mathrm{Al}_{2} \mathrm{O}_{3}: 5 \mathrm{SiO}_{2}: 1000 \mathrm{H}_{2} \mathrm{O},{ }^{7} \mathrm{a}$ commonly used clear solution composition for zeolite A coating formation, the cost of reagents may be reduced by more than 4 fold. Another benefit of the proposed method in coating preparation may be the provision of synthesis under distinctive conditions, where synthesis involves two simultaneous processes: the dissolution of clinoptilolite to provide necessary reactants and the reaction on the substrate to form zeolite A. In this technique, the coating properties, such as thickness and homogeneity, may be controlled and manipulated in a manner different than the existing methods.

\section{Conclusions}

A new concept was presented in this study for preparing synthetic zeolite coatings by using natural materials. In this context, it was shown that pure and crystalline zeolite A coatings could be prepared from natural clinoptilolite under hydrothermal conditions. A conventional synthesis temperature of $90^{\circ} \mathrm{C}$ and reaction periods of about 2.5-5.5 h were determined to be suitable conditions for obtaining zeolite A coatings on stainless steel. Utilizing proper alkalinity, alumina and clinoptilolite contents in the reaction mixtures assured relatively high crystallinity and purity of the coatings. Zeolite A tended to transform into hydroxysodalite after certain synthesis periods of time. In the reaction mixture, clinoptilolite mostly settled at the bottom of the reactor and was not in direct contact with the substrate. Clinoptilolite was gradually transformed into amorphous material while zeolite A formation started to take place in the reaction mixture as well as on the substrate. Clinoptilolite provided the silica necessary for zeolite synthesis in the alkaline reaction mixture containing alumina.

The thicknesses of the coatings increased with synthesis time. When conventional synthesis is applied using synthetic reactants, it is known that there is a strict limit to this thickness, especially for the very metastable zeolite A. Only very thin coatings of zeolite A, of about 5 $\mu \mathrm{m}^{7}$, are known to be obtained by conventional synthesis from clear solution compositions which are suitable for coating preparation. Although the highest mass equivalent thickness of zeolite A coatings obtained in this study was about $29 \mu \mathrm{m}$, as obtained by substrate heating method for $4.5 \mathrm{~h}$ synthesis at a water bath temperature of $75^{\circ} \mathrm{C}$, this may still be not enough for some applications. However, the success in preparation of zeolite A coatings from natural clinoptilolite by using the substrate heating method is very important. Zeolite A coatings could be prepared by using the substrate heating method even at temperatures as low as $30^{\circ} \mathrm{C}$ for the bulk of the reaction mixture. This may allow the preparation of relatively thick coatings at prolonged durations, since the reaction in the bulk of the reaction mixture may thus be suppressed for a quite long period of time.

The significance of using natural zeolite for preparing coatings of synthetic zeolites mainly lies in its economical profitability. In this manner, when mass-production of zeolite coatings becomes necessary for some applications, the costs of the resources used may be reduced. The involvement of two simultaneous processes in coating preparation from clinoptilolite, namely, the dissolution/transformation of clinoptilolite in the reaction mixture and the reaction taking place on the substrate, by the help of dissolved reagents, presents a new approach for zeolite coating preparation. This may allow obtaining coatings of different characteristics, such as thickness and homogeneity. The possibility of preparing coatings of different synthetic zeolites from various natural resources should also be investigated by using different synthesis conditions. 


\section{References}

1. Tatlier M, Erdem-Şenatalar A. The effects of thermal and mass diffusivities on the performance of adsorption heat pumps employing zeolite synthesized on metal supports. Microporous and Mesoporous Materials. 1999;28(1):195-203.

2. Rebrov EV, Mies MJM, de Croon MHJM, Schouten JC. Hydrothermal Synthesis of Zeolitic Coatings for Applications in Microstructured Reactors. In: Valtchev V, Mintova S, Tsapatis M. Ordered Porous Solids. Amsterdam: Elsevier; 2009. p. 311-334.

3. Lefevere J, Gysen M, Mullens S, Meynen V, Van Noyen J. The benefit of design of support architectures for zeolite coated structured catalysts for methanol-to-olefin conversion. Catalysis Today. 2013;216:18-23.

4. Mosca A, Hedlund J, Webley PA, Grahn M, Rezaei F. Structured zeolite $\mathrm{NaX}$ coatings on ceramic cordierite monolith supports for PSA applications. Microporous and Mesoporous Materials. 2010;130(1-3):38-48.

5. Yu M, Noble RD, Falconer JL. Zeolite membranes: microstructure characterization and permeation mechanisms. Accounts of Chemistry Research. 2011;44(11):1196-1206.

6. Nikolajsen K, Kiwi-Minsker L, Renken A. Structured Fixed-Bed Adsorber Based On Zeolite/Sintered Metal Fibre For Low Cocentration VOC Removal. Chemical Engineering Research and Design. 2006;84(7):562-568.

7. Erdem-Senatalar A, Tatlier M, Ürgen M. Preparation of zeolite coatings by direct heating of the substrates. Microporous and Mesoporous Materials. 1999;32(3):331-343.

8. Valtchev V, Hedlund J, Schoeman BJ, Sterte J, Mintova S. Deposition of continuous silicalite-1 films on inorganic fibers. Microporous Materials. 1997;8(1-2):93-101.

9. Tosheva L, Ng EP, Mintova S, Hölzl M, Metzger TH, Doyle AM. $\mathrm{IPO}_{4}-18$ seed layers and films by secondary growth. Chemistry of Materials. 2008;20(17):5721-5726.

10. Zhang H, Suszynski WJ, Agrawal KV, Tsapatsis M, Al Hashimi S, Francis LF. Coating of open cell foams. Industrial \& Engineering Chemistry Research. 2012;51(27):9250-9259.

11. Misaelides P. Application of natural zeolites in environmental remediation: A short review. Microporous and Mesoporous Materials. 2011;144(1-3):15-18.
12. Adamaref S, An W, Jarligo MO, Kuznicki T, Kuznicki SM. Natural clinoptilolite composite membranes on tubular stainless steel supports for water softening. Water Science \& Technology. 2014;70(8):1412-1418.

13. Swenson P, Tanchuk B, Gupta A, An W, Kuznicki SM. Pervaporative desalination of water using natural zeolite membranes. Desalination. 2012;285:68-72.

14. Hristov P, Yoleva A, Djambazov S, Chukovska I, Dimitrov D. Preparation and characterization of porous ceramic membranes for micro-filtration from natural zeolite. Journal of the University of Chemical Technology and Metallurgy. 2012;47(4):476-480.

15. Avila AM, Yu Z, Fazli S, Sawada JA, Kuznicki SM. Hydrogenselective natural mordenite in a membrane reactor for ethane dehydrogenation. Microporous and Mesoporous Materials. 2014;190:301-308.

16. de las Pozas C, Diaz Quintanilla D, Perez-Pariente J, RoqueMalherbe R, Magi M. Hydrothermal transformation of natural clinoptilolite to zeolites $\mathrm{Y}$ and $\mathrm{P}_{1}$ : influence of the $\mathrm{Na}, \mathrm{K}$ content. Zeolites. 1989;9(1):33-39.

17. Kazemian H, Modarress H, Kazemi M, Farhadi F. Synthesis of submicron zeolite LTA particles from natural clinoptilolite and industrial grade chemicals using one stage procedure. Powder Technology. 2009;196(1):22-25.

18. Kamali M, Vaezifar S, Kolahduzan H, Malekpour A, Abdi MR. Synthesis of nanozeolite A from natural clinoptilolite and aluminum sulfate; Optimization of the method. Powder Technology. 2009;189(1):52-56.

19. Kartal OE, Onal I. Synthesis of ZSM-5 from modified clinoptilolite and its catalytic activity in alkylation of benzene to ethylbenzene. Chemical Engineering Communications. 2008;195(8):1043-1057.

20. Shindo T, Nagai Y, Ikeuchi T, Ozawa S. Synthesis of MCM-41 with Zeolite-P from Natural Clinoptilolite for Silica-alumina Source Under Hydrothermal Conditions in Alkaline Media. International Journal of the Society of Materials Engineering for Resources. 2011;18(1):1-6.

21. Sirkecioğlu A, Erdem-Șenatalar A. Estimation of the zeolite contents of tuffaceous samples from the Bigadiç clinoptilolite deposit, western Turkey. Clays and Clay Minerals. 1996;44(5):686-692.

22. Ceyhan T, Tatlier M, Akçakaya H. In vitro evaluation of the use of zeolites as biomaterials: effects on simulated body fluid and two types of cells. Journal of Materials Science: Materials in Medicine. 2007;18(8):1557-1562. 